\title{
$\sqrt{ }$ Doctors with difficulties: why so few women? \\ EDITOR'S \\ CHOICE \\ J Firth-Cozens
}

Correspondence to:

Professor J Firth-Cozens, London

Deanery, Stewart House, 32

Russell Square, London WC1B

5DN, UK; jfirth-cozens@

londondeanery.ac.uk

Received 1 February 2008

Accepted 12 April 2008

\section{ABSTRACT}

The National Clinical Assessment Service (NCAS), an NHS organisation that assesses doctors and dentists referred to them because of perceived difficulties, has produced a report describing data arising from its first 4 years, showing that male doctors were referred to the service considerably more often than female doctors. Despite women accounting for $42 \%$ of the general practitioner medical workforce and $37 \%$ of the medical hospital and community (H\&C) workforce in 2004, only $13 \%$ of GPs and $20 \%$ of H\&C NCAS referrals were women. When the H\&C data were split into specialties, women were underrepresented proportionally in all specialties. This paper offers a review of possible reasons for these gender differences and in doing so contributes to the debates concerning problems in performance and also the costs of employing a growing proportion of women doctors. Firstly, it hypothesises that the NCAS data may be nonrepresentative of similar agency data, but finds that in disciplinary organisations of various types around the world, men are consistently over-represented. Secondly, it suggests that perhaps men are referred to such agencies more often than women because their employers are more lenient on women. There is no evidence for this, and it requires primary research to investigate it further. Finally, it considers gender differences in the attributes, beyond technical skills, that underpin a good doctor-patient relationship and finds that, on these attributes, women usually excel over men. In addition, far fewer women are disciplined for addiction. The implications of this for education and rehabilitation are considered. It concludes that any analysis of the economic costs of employing a greater proportion of female doctors must take into account the higher costs of men's litigation, discipline and retraining.

In a recent series of articles and editorials in the $B M J,{ }^{1-3}$ the question of the increasing proportion of women in medicine was debated, particularly as a study ${ }^{4}$ had found evidence that women consultants perform fewer patient episodes than men, potentially adding to the economic cost of selecting women doctors. However, it was pointed out ${ }^{1}$ that there may be other economic benefits emerging from their employment, which need to be taken into account; namely, that women appear to be considerably less likely than men to face any referral, litigation or discipline because of their performance as doctors. In England, a report ${ }^{5}$ describing data arising from referrals over the first 4 years of the National Clinical Assessment Service (NCAS) (box 1), showed that male doctors were referred to the service considerably more often than female doctors. In 2004, women accounted for $42 \%$ of the general practitioner (GP) medical workforce and $37 \%$ of the medical hospital and community (H\&C) workforce. However, they accounted for a much smaller proportion of NCAS referrals throughout the 4 years: only $13 \%$ of GPs and $20 \%$ of H\&C referrals were women. These differences were not explained by an age cohort effect nor by grade. When the $\mathrm{H} \& \mathrm{C}$ data were split into specialties, women were underrepresented proportionally in all specialties. For example, women surgeons represent $20 \%$ of the surgical workforce, but only $9 \%$ of surgical referrals were women; similarly, whereas women represent $42 \%$ of psychiatrists, only $24 \%$ of the psychiatrists referred were women. This paper develops the debate on gender and performance problems by offering possible reasons behind these data.

\section{ARE THE NCAS FIGURES CONTRARY TO DATA FROM OTHER SOURCES?}

Disciplinary and assessment agencies differ in countries around the world and from state to state within countries. However, a review of published reports shows that women doctors are consistently less likely to be disciplined, or have claims made against them, or be sufficiently impaired to seek or be offered help.

- Of 375 Californian doctors disciplined over 1 year, ${ }^{6} 32(9 \%)$ were women, significantly fewer than controls. When the gender differences for the offences were considered, most were disciplined for: negligence or incompetence (115 men and 12 women); drug use (40 men, two women) and alcohol use (45 men, seven women); sexual misconduct (36 men, one woman); and financial and tax fraud (32 men, three women).

- Of the 49 career grade doctors with problems in the Northern Region of the NHS, only six were women. ${ }^{7}$

- In the USA, after adjustment for all demographic factors, male doctors were found to be three times more likely than female doctors to be in the high claims category in terms of malpractice. ${ }^{8}$

- Of 107 doctors referred to the Norwegian Board of Health over 2 years, only 16 (15\%) were women, ${ }^{9}$ while of the 4004 GPs in Norway, 1225 (31\%) are women.

- Of 155 referred to the Catalan "service for impaired doctors" with alcohol and drug abuse, only $20 \%$ were women. ${ }^{10}$

- In the USA, only seven out of 100 doctors treated for alcohol problems were women. ${ }^{11}$

- Almost all doctors referred for sexual misconduct are male. ${ }^{12}$

These data from various studies around the world consistently show that women doctors are referred or disciplined significantly less often than male doctors. Although the proportion of women in the medical workforce as a whole (or in a control 


\section{National Clinical Assessment Service (NCAS)}

NCAS supports healthcare organisations to manage doctors and dentists whose performance gives cause for concern. NCAS provides telephone advice to 700 new cases each year. They offer a comprehensive assessment of practitioners' performance and produce recommendations so that, wherever possible, the practitioner can get back to safe practice.

group) is not always described, these differences are large and consistent, suggesting that NCAS data reflect those from other agencies around the world.

\section{DO REFERRING AGENCIES TREAT PROBLEMS POSED BY MALE DOCTORS MORE SEVERELY THAN THOSE POSED BY WOMEN DOCTORS?}

There is little research relating to this possibility: none looks in depth at the roots of decision-making behind referral, nor whether the process differs in terms of gender or type of problem. Evidence exists, however, concerning what happens when colleagues see problems in other staff; for example, people are less likely to report colleagues if they show insight or apologise for what they have done. ${ }^{13}$ Were women doctors found to be more likely to accept and apologise when things go wrong, then this may account for some of the differences. This leads to the third possible reason for the data: that there are skills and characteristics shown more abundantly by women that act as protectors against poor practice and/or referral.

\section{ARE WOMEN DOCTORS REFERRED LESS OFTEN BECAUSE OF GENDER DIFFERENCES IN PARTICULAR SKILLS AND CHARACTERISTICS?}

In comparisons of academic results and clinical care, there are only few and slight differences found between men and women. For example, although female medical students may do better in their final undergraduate exams than male students, ${ }^{14}$ in technical procedures there are no significant differences. ${ }^{15}$ However, there are various characteristics found more strongly in women than in men that may help to explain referral data, as many of them reflect indicators of good medical practice. For example, communication skills are often found to be superior in women, and this may lead to more effective interactions and relationships with patients, lessening the chance of complaints and litigation. This and other skills and characteristics likely to influence referral are discussed below.

\section{Emotional intelligence}

Emotional intelligence involves good self-awareness and selfmanagement, social awareness and relationship management. ${ }^{16}$ There are strong indications for its importance and a number of studies show that higher emotional intelligence is related to superior academic, clinical and other forms of performance $e^{17-19}$ as well as ethical decision-making. ${ }^{20}$ Most studies show that women have higher levels of emotional intelligence than men. ${ }^{19} 21$

\section{Integrity}

Women score more highly on overt integrity tests than men do, ${ }^{22}$ whereas egoism, which relates to deviance in general, is lower in women. ${ }^{23}$

\section{Personality}

Studies using psychometrics based on the Big 5 (extraversion, openness, conscientiousness, agreeableness and low neuroticism) to look at performance and personality suggest that conscientiousness is particularly important. For example, a study of female pilots using the Big 5 found that they were more extraverted, agreeable and conscientious than male pilots. The study concluded that, as these characteristics had been shown to be the "right stuff" for pilots, women would make better pilots than men. ${ }^{24}$

The risky personality, involving sensation-seeking and impulsivity, is likely to create particular problems in terms of patient safety $^{25}$ and is generally found to be greater in men. ${ }^{26}$ In addition, there is evidence of an interaction between sensationseeking, self-esteem and gender in risk-taking: high sensationseeking, low self-esteem and being male make risk-taking most likely, and low sensation-seeking, high self-esteem and being female make risk-taking least likely. ${ }^{27}$

Another aspect of personality, empathy, is linked to both emotional and general intelligence, and is seen as an important ability in at least some forms of medicine. Empathy has both a cognitive capacity, allowing insight into the experiences of others, and an emotive capacity, enabling a response to these experiences, and both types are higher in women. ${ }^{28}$

\section{Communication skills}

Communication skills are an essential tool in good patient care, ${ }^{29}$ and women doctors have generally been found to be superior in communication skills than men. A meta-analytical review ${ }^{30}$ showed that they:

- have longer consultations

- are more patient-centred

- show more partnership behaviours

- engage in more positive talk and emotionally focused talk

- ask more psychosocial questions and counsel more psychosocially

and their patients speak more.

\section{Mental health}

In terms of mental health, findings are not always consistent. Although in Norway no gender differences in mental health problems in junior doctors were found, ${ }^{32}$ some longitudinal studies show that women doctors are more depressed. ${ }^{33}$ However, this occurs only after graduation, suggesting that the cause may be more job-related, particularly as it is only women hospital doctors (not GPs) who show this difference.

In other areas, such as addiction and particular personality disorders, it becomes clearer why some men find themselves more often in disciplinary situations. For example, referrals to the Catalan "impaired doctors' scheme" show that the largest gender difference for personality disorders concerns greater antisocial and aggressive disorders in male than in female doctors. ${ }^{10}$ In terms of alcohol and other drug use, studies are unanimous in finding that women use these considerably less than men, and are disciplined for their use much less often. ${ }^{10} 11$ Where women doctors are alcoholic, this is largely related to depression, [34] although this may well be a factor for male alcoholics too.[35] Alcohol use by women in general has risen considerably in the last few years, and this is likely to be reflected in doctors too, so these findings may change in the future. 


\section{CONCLUSIONS}

This discussion makes it clear that gender differences in NCAS referral data are reflected in other data from around the world. Although they may suggest it, these data do not show that women doctors are superior to men-only that those within the small group of doctors who are referred for assessment or discipline or experience litigation are much more likely to be male than female. It provides a number of potential reasons for this, the testing of which provides an interesting and important research agenda. In addition, it allows organisations such as deaneries and medical schools to use some of the potentially important differentiating factors for assessment, education and intervention-for example, in relation to communication skills, handling impulsivity, recognising and understanding alcohol abuse, developing emotional intelligence, and knowing when to go for help. Above all, it shows that any comparison of the economic costs of employing male and female doctors is much more complex than some have suggested. Moreover, the quality of patient care more generally implied by these findings may in itself outweigh any arguments to reduce the proportion of women doctors.

Competing interests: There are no competing interests or funding issues involved although the author was commissioned by NCAS to consider reasons behind their data when the report was first produced.

\section{REFERENCES}

1. Firth-Cozens $\mathbf{J}$. Effects of gender on performance in medicine. BMJ 2008;336:731-2

2. McKinstry B. Are there too many female medical graduates? Yes. BMJ 2008;336:748.

3. Dacre J. Are there too many female medical graduates? No. BMJ 2008;336:749

4. Bloor K, Freemantle N, Maynard A. Gender and variation in activity rates of hospital consultants. J $R$ Soc Med 2008;1101:27-33.

5. National Clinical Assessment Service. Analysis of the first four years' referral data. London: National Patient Safety Agency, 2006.

6. Morrison J, Morrison T. Psychiatrists disciplined by a State Medical Board. Am J Psychiatry 2001;158:474-8.

7. Donaldson LJ. Doctors with problems in an NHS workforce. BMJ 1994;308:1277-82.

8. Taragin MI, Wilczek AP, Karns E, et al. Physician demographics and the risk of medical malpractice. Am J Med 1992;93:537-42.

9. Bratland SZ, Hunskår S. Medico-legal assessments of complaints against general practitioners. Tidsskr Nor Laegeforen 2006;126:166-9.

10. Lusilla $\mathbf{P}$, Gual A, Navarro B, et al. Gender differences among impaired doctors International Conference on Physician Health, Ottawa, 2006.

11. Gallanter M, Talbott D, Galllegos K, et al. Combined alcoholics and professional care for addicted physicians. Am J Psychiatry 1990;147:64-8.

12. Quadrio C. Sex and gender and the impaired therapist. Aust NZ J Psychiatry 1992;26:346-63.
13. Firth-Cozens J, Redfern N, Moss F. Confronting errors in patient care: the experiences of doctors and nurses. Clinical Risk 2004;10:184-90.

14. McDonough CM, Horgan A, Codd MB, et al. Gender differences in the results of the final medical examination at University College Dublin. Med Educ 2000;34:30-4.

15. Chafin CC, Tolley EA, George CM, et al. Gender differences in metered-dose inhalerspacer device technique. Pharmacotherapy 2000;20:1324-7.

16. Chernis C, Goleman D. The emotionally intelligent workplace. San Francisco: JosseyBass, 2001.

17. Austin EJ, Evans P, Goldwater R, et al. A preliminary study of emotional intelligence, empathy and exam performance in first year medical students. Pers Individ Dif 2005:36:1395-405.

18. Lewis ES. A study of emotional intelligence, cognitive intelligence and clinical performance of physcal therapy students. Dissertation Abstracts International: Section B: Sciences and Engineering 2004;65:205

19. Alloway BM. Emotional intelligence and extrinsic career success: a comparison of gender and management. Dissertation Abstract International: Section B: Science and Engineering 2005;66:601.

20. Scott BS. The relationship between emotional intelligence and ethical decision making. Dissertation Abstracts International: Section A: Humanities and Social Sciences 2005;65:2899.

21. Carrothers RM, Gregory SW, Gallagher TJ. Measuring emotional intelligences of medical school applicants. Acad Med 2000;75:456-63.

22. Ones DS, Viswesvaran C. Gender, age and race difference on overt integrity tests: results across four large-scale job applicant datasets. J Appl Psychol 1998;83:35-42.

23. Weigel RH, Hessing DJ, Elffers H. Egoism: concept, measurement and implications for deviance. Psychology, Crime \& Law 1999;5:349-78.

24. King RE, McGlohn SE, Retzlaff PD. Female United States Air Force pilot personality: the new right stuff. Mil Med 1997;162:695-7.

25. Firth-Cozens J, Cording H, Ginsburg R. Can we select health professionals who provide safer care? Qual Saf Health Care 2003;12(Suppl1):16-20.

26. Vermeiren R, Deboutte D, Ruckkin V, et al. Antisocial behaviour and mental health Eur Child Adolesc Psychiatry 2002;11:168-75.

27. Davis RS. Audience segmentation for communication interventions: the roles of sensation-seeking, self-esteem and gender in sexual risk-taking. Dissertation Abstracts International: Section A: Humanities and Social Sciences 2000;60:4232.

28. Shanafelt-Tait D, West C, Zhao X, et al. Relationship between increased personal well-being and enhanced empathy among internal medicine residents. J Gen Intern Med 2005;20:559-64

29. Davenport DL, Henderson WG, Mosca CL, et al. Risk-adjusted morbidity in teaching hospitals correlates with reported levels of communication and collaboration on surgical teams but not with scale measures of teamwork climate, safety climate or working conditions. J Am Coll Surg 2007;205:778-84.

30. Roter DL, Hall JA, Aoki Y. Physician gender effects in medical communication: a meta-analytic review. JAMA 2002;288:765-64.

31. Wilkinson SM, Leliopoulou C, Gambles M, et al. Can intensive three-day programmes improve nurses' communication skills in cancer care? Psycho-oncology 2003:12:747-59.

32. Tyssen R, Vaglum P, Gronvold NT, et al. The mpact of job stress and working conditions on mental health problems among junior house officers. A nationwide Norwegian prospective cohort study. Med Educ 2000;34:374-84.

33. Firth-Cozens. A perspective on stress and depression. In: Cox J, King J, Hutchinson A, et al.(eds). Understanding doctors' performance. Oxford: Radcliffe Publishing, 2005.

34. Bissell L, Skorina JK. One hundred alcoholic women in medicine. JAMA 1982;257:2932-44.

35. Olenick NL, Chgalmers DK. Gender-specific drinking styles in alcoholics and nonalcoholics. J Stud Alcohol 1991;52:325-30. 